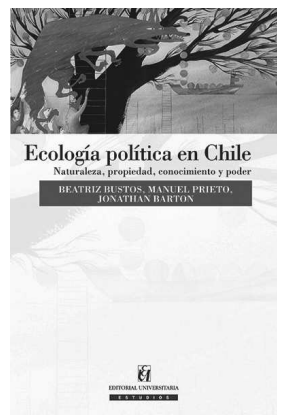

\title{
Beatriz Bustos, Manuel Prieto y Jonathan Barton. Ecología Política en Chile: naturaleza, propiedad, conocimiento y poder.
}

\author{
Santiago de Chile: Editorial Universitaria, 2015. 275 p. \\ ISBN: 9561124653
}

\author{
Francisco Molina Camacho ${ }^{1}$
}

\begin{abstract}
El presente libro es sin duda un aporte. Navega por las aguas turbulentas del pensamiento crítico moderno, articulando teoría y práctica sobre un telón de fondo que cada vez se torna más urgente: la relación naturaleza/sociedad. De esta manera, y desde el confín de la tierra, este libro es capaz de analizar de forma crítica dicha relación respondiendo, a ratos implícitamente, a la necesidad epistemológica de descolonizar el saber. Así, indagando en una ecología política "tercermundista", es capaz de dar vida a modos alternativos de pensar, que se manifiestan en la reflexión crítica de académicos (tanto chilenos como foráneos) que han visto en Chile las consecuencias de un proyecto ambiental neoliberal que mercantiliza la naturaleza.
\end{abstract}

La aproximación conceptual de este libro se estructura en torno a cuatro ejes clave: "naturaleza, propiedad, conocimiento y poder". Sin necesidad de jerarquías ni comparaciones, estos conceptos logran articular las principales contribuciones de la ecología política desde la década de 1970 a la fecha, y permiten afrontar -a mi juicio- su "talón de Aquiles": ofrecer un enfoque con límites claros. Así, este libro presenta dos aciertos. Mientras el primero radica en su capacidad de analizar los cuatro ejes señalados ante-

1 Universidad Diego Portales (Chile) E-mail: francisco.molina@mail.udp.cl riormente por medio de elementos teórico/ conceptuales claros y precisos, el segundo se funda en la riqueza de casos de estudio que se amparan en dichos ejes tensionándolos, de una manera diversa y persuasiva.

\section{Naturaleza}

Reconocer que la naturaleza es "producida tanto discursiva como materialmente por medio de procesos sociales" (p. 22) surge ya como un mantra en la ecología política y este libro así lo define. En esta línea, no solo da cuenta de la perspectiva posestructuralista donde discursos y narrativas marcan el análisis obviando fronteras entre naturaleza y cultura, sino que también reflexiona sobre la producción social de la naturaleza -desde una óptica postmarxista- asumiendo el principio básico de que "Ia naturaleza separada de la sociedad no tiene sentido" (p. 25). De esta manera, ideas posestructuralistas y estructuralistas se funden en este libro "desnaturalizando la naturaleza" para dar respuesta a interrogantes tan relevantes para el devenir de nuestro país (y de la región), asociadas a identificar quiénes son los dominadores de los imaginarios sobre naturaleza a los cuales estamos expuestos, así como a reflexionar en torno al tipo de naturaleza que como sociedad neoliberal hemos producido.

Respuestas a este tipo de preguntas se observan en los capítulos de Ogden y Holmes, y 
de Rozzi, donde ambos desde distintos enfoques y aproximaciones dan cuenta de la necesidad de crear nuevos lenguajes y códigos que permitan armonizar la relación entre la naturaleza y las sociedades. En específico, el capítulo "Involucramientos globales del bosque, incluso en el fin del mundo" de Ogden y Holmes da cuenta de cómo la naturaleza emerge de "ensamblajes socioecológicos que se construyen a través de articulaciones globales y de la política global" (p. 64), redefiniendo y condicionando su devenir. Tierra del Fuego, a pesar de su lejanía y "salvajismo" se muestra como un territorio preso de tensiones políticas disímiles -tal como se observa en los bosques del Parque Natural Karukinkaque van desde el antagonismo entre la "lógica especulativa" del capitalismo neoliberal y el reconocimiento sagrado de los bosques; hasta las contradicciones de un Estado que otorga libertades y restricciones sobre la naturaleza, sin una secuencia lógica clara.

En esta línea, "Ética biocultural: una ampliación del ámbito socioecológico para transitar desde la homogeneización biocultural hacia la conservación biocultural" de Rozzi reposiciona y redefine la importancia de la dimensión ética. En contraste con las éticas deontológicas y utilitaristas, ambiental anglosajona, y moderna; promueve la ética biocultural como un paradigma que "demanda un diálogo intercultural" (p. 91) acoplando hábitos humanos con hábitats, e incluyendo interrelaciones con las comunidades de cohabitantes (otras especies animales y vegetales). Así, por medio de una reflexión crítica sobre la migración rural-urbana, la homogeneización lingüística y el reduccionismo que presenta la filosofía en la actualidad, Rozzi da cuenta de la urgencia de un cambio epistemológico. Esto, a través de un nuevo enfoque metodológico -denominado la filosofía ambiental del campo (FILAC) - que permita un tránsito desde una homogenización biocultural hacia una conservación biocultural.

\section{Propiedad}

El asumir que la propiedad es un derecho y no una cosa es clave no solo para este libro, sino que también para comprender el alcance que dicha distinción tiene en nuestro país. De esta distinción subyace que la propiedad es capaz de establecer "relaciones en- tre personas con respecto a los objetos apropiados (...) [además de] (...) "estar facultada jurídicamente para hacer valer sus pretensiones de uso y beneficio sobre dicho objeto" (p. 28). Esto, en términos prácticos ha condicionado fuertemente la gestión ambiental, al entenderse a la propiedad privada como una solución natural frente a la desidia de la propiedad colectiva. Este libro así lo declara asumiendo que dicho entendimiento responde ya sea a un error epistemológico o a un proyecto político, ambos embebidos de dinámicas de poder y segregación. De esta forma, este libro nos invita a asumir que la propiedad, en tanto derecho, es miope en su capacidad de analizar las relaciones de poder en torno a la naturaleza, y profundiza en la importancia de extender el estudio de propiedad en tanto acceso, invitándonos a reflexionar sobre los contextos en los cuales se aplican dichos derechos o sobre quienes son los ganadores y perdedores de dicha aplicación.

Así, la propiedad es abordada como una herramienta de gobernanza ambiental no exenta de contradicciones. La definición de los recursos naturales en el Código Civil como un "bien nacional de uso público" y la asignación de derechos de propiedad privados sobre dichos recursos surge como un elemento de tensión central, el cual es retratado claramente por Tecklin y Prieto en este libro tanto en los derechos asociados a la acuicultura industrial, la pesca artesanal y las organizaciones indígenas; como en los derechos de agua, respectivamente. Por una parte, "La apropiación del litoral de Chile: la ecología política de los derechos privados en torno al mayor recurso público del país" de Tecklin es un esfuerzo por demostrar cómo la explotación de recursos naturales en las costas chilenas se ha distribuido de manera desigual. Mediante un análisis de la propertización -entendida como la "creación y asignación de derechos de propiedad" (p. 122) - utiliza elementos de la ecología política como territorialización, la tensión entre autoridad y derechos de propiedad, y el rol de los imaginarios geográficos para cuestionar el control y el poder que se esconde tras la gobernanza ambiental. En concreto, realiza un análisis crítico de cómo el borde costeromarino chileno posee un administración burocrática, incierta y desigual. 
Por otra parte, la reflexión crítica que tiene Prieto en el capítulo "La ecología (a) política del modelo de aguas chileno" permite desmitificar el carácter apolítico de dicho modelo de gestión, rompiendo con la idea neoclásica de que el mercado puede ser observado "como un fenómeno guiado por leyes naturales, universales y neutrales" ( $p$. 147). Así, da cuenta cómo la catalaxia [orden espontáneo del mercado] valida inequidades al momento de valorizar el agua y de determinar el destino de sus flujos bajo un imaginario de neutralidad que no es tal. En efecto, y aquí radica el principal aporte de Prieto, la ecología política surge como un lente capaz de desenmascarar dicho error epistemológico al dar cuenta de sus consecuencia materiales tanto ambientales como sociales. A través de un repaso por el modelo de gestión hidroeléctrico y de los mercados de agua en el desierto de Atacama, este capítulo da cuenta cómo el modelo de agua en Chile instrumentaliza la naturaleza anclado en derechos de propiedad que aseguran y perpetúan la expansión del modelo capitalista.

\section{Conocimiento}

El conocimiento surge como un elemento vital al momento de reflexionar en torno a los procesos ecológicos. Por lo mismo, la ecología política ha tomado dicho conocimiento (científico o vernacular) para indagar en la relación entre naturaleza y sociedad, ya sea utilizándolo como base argumentativa/normativa para analizar problemas sociales, y/o para cuestionar su mecanismo de producción en tanto es (mal) usado o disputado por las partes involucradas. Este libro da cuenta del trasfondo político de dicho conocimiento enfatizando en su capacidad de construir socialmente los problemas ambientales, desmitificando su supuesta neutralidad, y confrontando las inequidades que se observan entre los saberes sobre naturaleza. Sobre esto último, el presente libro cuestiona ontológicamente el conocimiento científico chileno y su relevancia para los problemas ambientales que enfrenta el país, al estar supeditados al logro de soluciones "eficientes" y "óptimas" que están al servicio de las políticas neoliberales.

De esta manera, el conocimiento es analizado críticamente en este libro. Tanto Sepúl- veda y Sundberg como Bustos son capaces de cuestionar la veracidad del conocimiento científico dando cuenta de su relatividad y amparo bajo el poder. En concreto, y a través de una crítica a los alcances ontológicos de la ecología política, Sepúlveda y Sundberg en el capítulo "Apertura ontológica, multiplicidad y performación: explotando una agenda posthumanista en ecología política a partir del desastre del río Cruces en Valdivia" promueven una "apertura ontológica" argumentando que "la realidad descrita por teorías y hechos científicos no es algo exterior (...) sino el resultado material -la fabricación o performación- de mundos" (p.168). En esta línea, critican la singularidad ontológica de la ecología política al tratar de manera internamente homogénea "lo natural" y "lo no humano", y al presentar como "perspectivas" de "la" realidad a las formas no modernas de conocimiento. En concreto, a través del desastre del río Cruces, ambas autoras argumentan la forma como dicho desastre abrió las 'cajas negras' del conocimiento científico fracturando ontológicamente no solo dicho conocimiento sino que la institucionalidad ambiental en su totalidad.

En el caso de Bustos se observa claramente un quiebre entre producción de conocimiento científico y la política ambiental que tiene Chile en la actualidad. En el capítulo "Producción de Conocimiento en Chile y el caso de la crisis salmonera" queda de manifiesto la forma como la epidemia de anemia infecciosa del virus del salmón (ISA) desmanteló la poca capacidad que tiene la comunidad científica de intervenir en las políticas públicas. La privatización del conocimiento en las reformas neoliberales de comienzos de la década de 1980 y, consecuentemente, la entrada de nuevos actores y "sitios" en este mercado, ha exacerbado la brecha entre comunidad científica e industria, viéndose claramente ejemplificado en este capítulo en la industria del salmón. En esta, el foco de la investigación científica fue "recuperar rápidamente su valor de mercado por sobre el rol destructivo de las prácticas productivas empresariales (...) o el ecosistema donde se inserta" (p. 206), denotando que la industria chilena está fuertemente inclinada hacia un tipo de conocimiento -el aplicado- con el objeto de acelerar su producción. 
Poder

En lo que respecta al poder, este libro es capaz de constatar un elemento básico de la ecología política: esta disciplina "surge como consecuencia del reconocimiento de que las transformaciones ambientales están basadas en actores políticos $y$, por consiguiente, [en] relaciones de poder" (p. 42). En este sentido, el poder está en todas partes y de manera subyacente logra inmiscuirse en las relaciones entre las sociedades y la naturaleza. Así, en este libro el poder se constituye en un eje transversal que cruza los principios básicos de los tres ejes mencionados anteriormente. Esto, debido a que no solo es capaz de incidir en las construcciones y/o producciones sociales que hacemos sobre la naturaleza, sino que también viabiliza las inequidades que tanto la propiedad como el conocimiento logran instalar en tanto herramientas de gobernanza ambiental al servicio del neoliberalismo.

En este contexto, el poder forma parte de una reflexión interesante en los capítulos de Palomino-Schalscha, y de Román y Barton, donde se analiza cómo las políticas neoliberales han comodificado la naturaleza y transformado territorios bajo mecanismos de poder subyacentes en las industrias turísticas, forestales y salmoneras. En el caso específico de Palomino-Schalscha, el capítulo "Ejercitando el poder en tiempos neoliberales: resistencia, comodificación y emprendimiento en Alto Biobío" reflexiona en torno "al poder y las posibilidades de resistencia en un contexto marcado por discursos universalistas e inmovilizantes acerca del neoliberalismo" ( $p$. 214). En este sentido, y a través del análisis de la red de senderos pewenche Trekaleyn, Palomino-Schalscha demuestra empíricamente formas locales de resistencia al proyecto neoliberal. De esta manera, constata que a través procesos de organización colectiva, de resignignificación de lo cotidiano, y de apertura al emprendimiento turístico, esta red ha logrado demostrar que el proyecto neoliberal "no es un proyecto inamovible y totalizante" (p. 229), sino que es resistible por medio de prácticas transformativas de reapropiación y negociación.
En este misma línea, en el capítulo "Una ecología política de las transformación territoriales en Chile: Poder y gobernanza en los sectores forestal y salmonero" Román y Barton analizan las transformaciones territoriales que han traído consigo las actividades forestales y salmoneras. Los procesos de acumulación de capital, y los impactos sociales, ambientales y económicos a los que se exponen las comunidades aledañas a dichas actividades, son analizadas en este capítulo bajo el concepto de glocalización -noción que permite comprender la coexistencia entre lo local y lo global en diferentes escalas- reconociendo los distintos niveles en los cuales deambula el poder. Así, asumiendo que las relaciones de poder deben "considerar a los actores en diversas redes, escalas y relaciones, [y] no solamente a los actores localizados en un territorio específico" (p. 244), reflexionan en torno a cómo el nexo Estadocapital se da en ambas industrias como un expresión hegemónica de las élites políticas, donde la incorporación de actores periféricos solo se 'activa' en contextos de conflictos ambientales y territoriales.

\section{Reflexión final}

A modo de síntesis, el libro "Ecología Política en Chile: Naturaleza, propiedad, conocimiento y poder" da cuenta de un trabajo sistemático y serio que busca analizar la realidad chilena desde una perspectiva crítica. En esta línea, surge como un punto de partida hacia el entendimiento del trasfondo epistemológico que se esconde tras la gran cantidad de conflictos socioambientales que hoy existen en Chile. A través de un análisis teórico y empírico, este libro desenmascara la incidencia negativa que ha tenido el neoliberalismo en nuestro país, y nos invita a resistir sus efectos homogeneizantes, resaltando la pluralidad, la interculturalidad y la diversidad -tanto natural como cultural- como banderas de lucha. 